\title{
Scalability of Surface PM Machines With Concentrated Windings Designed to Achieve Wide Speed Ranges of Constant-Power Operation
}

\author{
Ayman M. EL-Refaie, Member, IEEE, and Thomas M. Jahns, Fellow, IEEE
}

\begin{abstract}
Previous work has shown that it is possible to design surface permanent magnet (SPM) synchronous machines, using fractional-slot concentrated windings to achieve wide speed ranges of constant-power operation. A closed-form analytical technique is now available to rapidly analyze candidate SPM machine designs using concentrated windings and tune them to meet the critical condition for optimal flux weakening. This analytical tool is used to demonstrate that optimal flux weakening can be achieved in SPM machines that are varied over wide ranges in several key dimensions including machine pole numbers, diameter-to-length aspect ratios, and output power ratings. Performance requirements for a $6-\mathrm{kW}$ direct-drive automotive starter/alternator machine are used as the starting point for the scalability investigation. Finite element analysis results are presented to confirm the validity of key results in this investigation.
\end{abstract}

Index Terms-Flux weakening, fractional-slot concentrated windings, permanent magnet synchronous motors, scalability.

\section{INTRODUCTION}

$\mathbf{R}$ ECENT work has demonstrated that, contrary to its general reputation, surface permanent magnet (SPM) synchronous machines can be designed to achieve wide speed ranges of constant-power operation [1], [2]. The key to this newfound capability is the replacement of conventional distributed windings in the stator of a SPM machine with fractional-slot concentrated windings.

The adoption of fractional-slot concentrated windings makes it possible to significantly increase the machine's characteristic current [3], defined as

$$
I_{\mathrm{ch}} \equiv \frac{\Psi_{\mathrm{m}}}{L_{d}}[\mathrm{~A} \mathrm{rms}]
$$

where $\Psi_{\mathrm{m}}$ is the rms magnet flux linkage and $L_{d}$ is the $d$-axis stator inductance (equal to the $q$-axis inductance for SPM machines). More specifically, the conditions for optimal flux-weakening operation can be achieved by designing the machine so that its characteristic current equals the rated

Manuscript received August 26, 2005; revised August 26, 2005. This work is supported in part by the Massachusetts Institute of Technology (MIT)/Industry Consortium on Advanced Automotive Electrical/Electronic Components and Systems. Paper no. TEC-00123-2005.

A. M. EL-Refaie was with the Department of Electrical and Computer Engineering, University of Wisconsin-Madison, Madison, WI 53706 USA. He is now with the Electrical Machines and Drives Laboratory, GE Global Research Center, Niskayuna, NY 12309 USA (e-mail: elrefaie@research.ge.com).

T. M. Jahns is with the Department of Electrical and Computer Engineering, University of Wisconsin-Madison, Madison, WI 53706 USA (e-mail: jahns@engr.wisc.edu).

Digital Object Identifier 10.1109/TEC.2006.874221

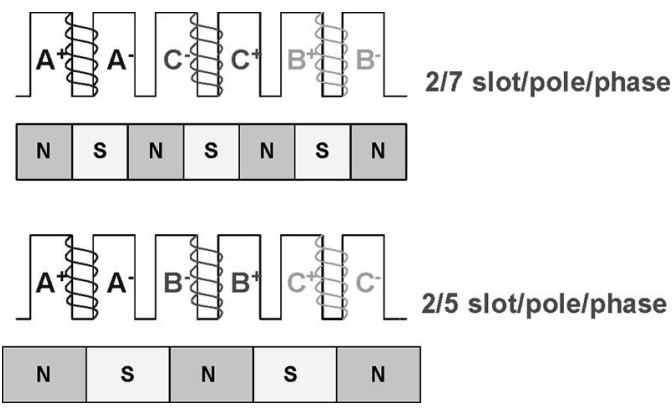

Fig. 1. Developed views of basic repeating units for fractional-slot concentrated winding SPM machines in two major families: SPP $=2 / 7$ and $\mathrm{SPP}=2 / 5$.

current value (i.e., $I_{\mathrm{ch}}=I_{\mathrm{R}}$ where $I_{\mathrm{R}}$ is the rated current of the machine) [4], [5].

The use of conventional distributed windings in SPM machines with integral values of slot/pole/phase (SPP) makes it difficult to meet the conditions for optimal flux weakening. More specifically, the machine phase inductance of SPM machines with distributed windings tends to be low, leading to characteristic current values that significantly exceed the machine's rated current. The low magnetic permeability of the permanent magnets in the machine's air gap is a major contributing factor that causes the low inductance. High values of characteristic current lead to rapid drops in the machine's torque and power production capabilities when the machine spins at speeds above its rated speed.

In contrast, the introduction of fractional-slot concentrated windings in appropriate configurations makes it possible to significantly increase the SPM machine's phase inductance. With proper design, the value of the characteristic current can be lowered and tuned to match the machine's rated current, achieving the conditions for optimal flux weakening. By introducing appropriate control for the flux weakening regime, such a machine can achieve very wide speed ranges of constant-power operation.

Previous work has shown that the choice of fractional-slot winding configuration has a major impact on the performance characteristics of the resulting SPM machine. In particular, it has been shown that stator winding configurations falling into the families of SPP $=2 / 5$ or SPP $=2 / 7$ are particularly well suited for SPM machines designed to achieve optimal fluxweakening conditions [1], [6], [7]. Fig. 1 shows the basic statorrotor repeating unit for each of these two winding configuration families. Candidate winding configurations consist of all even integral multiples of these basic building blocks. 
The air gap flux-density distributions produced by fractionalslot concentrated winding configurations are rich in harmonics and subharmonics of the fundamental spatial frequency set by the rotor poles. The presence of these harmonics cannot be ignored, but they significantly complicate any attempts to apply classical $d q$ analysis techniques.

A general closed-form analytical technique for analyzing SPM machines equipped with fractional-slot concentrated windings has been developed to overcome this obstacle [1], [8]. Initial application of this analysis tool to a 6-kW direct-drive SPM motor for automotive applications has led to a promising design that can achieve a wide constant-power speed range. Finite element analysis (FEA) has been used to confirm the accuracy of the closed-form analysis tool.

The objective of this paper is to apply the closed-form analytical tool to investigate the scalability of the fractional-slot concentrated winding approach for achieving optimal flux weakening in the SPM machines. In particular, this paper investigates the suitability of this approach for achieving wide speed ranges of constant-power operation with changes in the number of poles, the machine aspect ratio (i.e., diameter-to-length ratio), and the machine output-power rating. The impact of such scaling on a wide range of machine design parameters and performance metrics will be discussed.

A set of performance requirements drawn from a 6-kW directdrive automotive starter/alternator application [9] is used as the starting point for this investigation. FEA is used to confirm the validity of these new designs.

\section{OPtimal FluX-Weakening SCAlability Results}

The starting point for this scalability investigation is a set of performance requirements for an SPM motor that calls for $4-\mathrm{kW}$ output power at $600 \mathrm{r} / \mathrm{min}$ rising linearly to $6 \mathrm{~kW}$ at $6000 \mathrm{r} / \mathrm{min}$. This 10:1 motor speed range of (nearly) constant-power delivery is based on the complementary generating requirements for a direct-drive automotive starter/alternator machine that has been previously investigated [9].

The baseline machine used for these scalability investigations is a fractional-slot concentrated winding SPM machine with 36 stator slots (s) and 42 rotor poles (p) (36-s/42-p) that is a member of the SPP $=2 / 7$ family [1]. To minimize the number of variables that are being changed during the following design studies, some of the key machine variables are held constant. For example, the air gap length is held fixed at $0.635 \mathrm{~mm}$. In addition, it is assumed that $\mathrm{NdFeB}$ permanent magnets are available with remanent flux density $\left(B_{\mathrm{r}}\right)$ values that can be adjusted at will to any value up to $1.2 \mathrm{~T}$.

\section{A. Slot/Pole Number Scalability}

Recent work has shown that machine designs with either 2/7 or 2/5 SPP emerge as the best candidates for achieving optimal flux weakening in three-phase SPM machines with fractionalslot concentrated windings [1]. To explore the scalability of the concentrated-winding SPM machine with the number of poles, three different 6-kW motor designs belonging to the SPP $=2 / 7$ family have been developed, using 24-s/28-p, 36-s/42-p, and

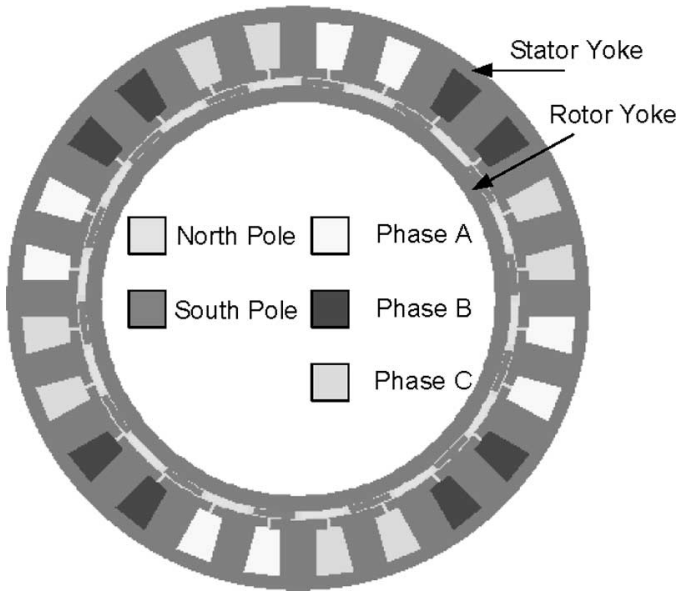

Fig. 2. Cross section of 6-kW SPM machine with 24 slots and 28 poles $(\mathrm{SPP}=2 / 7)$.

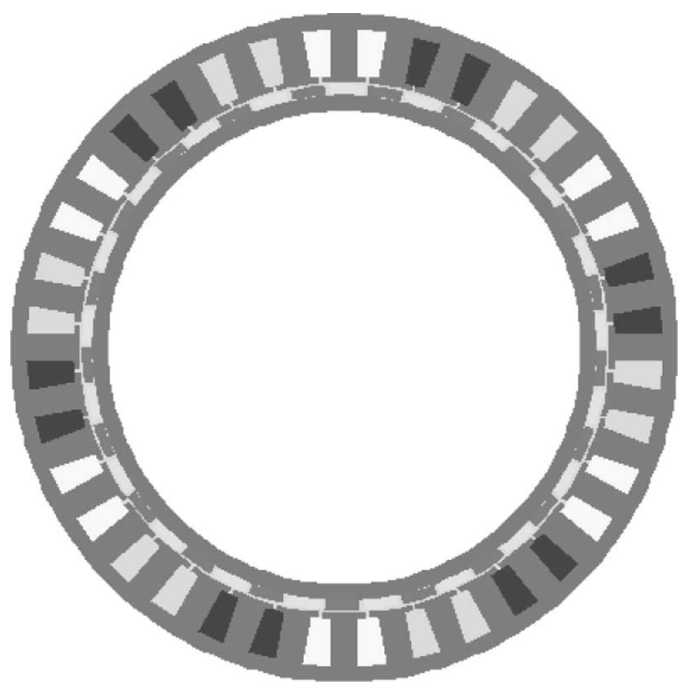

Fig. 3. Cross section of 6-kW SPM machine with 36 slots and 42 poles $(\mathrm{SPP}=2 / 7)$.

48-s/56-p combinations. The cross sections of these designs are shown in Figs. 2-4.

In addition, a 36-s/30-p design belonging to the $\mathrm{SPP}=2 / 5$ family has been developed for the same set of specifications, using a basic repeating unit consisting of six stator poles and five rotor poles. The cross section of this design is shown in Fig. 5. All of these four designs have the same stator outer diameter $(272 \mathrm{~mm})$ and active length $(60 \mathrm{~mm})$. The key parameters and performance metrics of the four machine designs are summarized in Table I.

All four of these SPM machines were designed to meet the condition for optimal flux weakening presented in Section I [1]. Values in Table I show that all four designs have nearunity values of the flux-weakening index (FW_index), defined as the ratio of the machine's characteristic current to the rated current. The calculated power versus speed envelopes of the four SPM machines are nearly identical. An example of these power capability envelopes is shown in Fig. 6, confirming that 


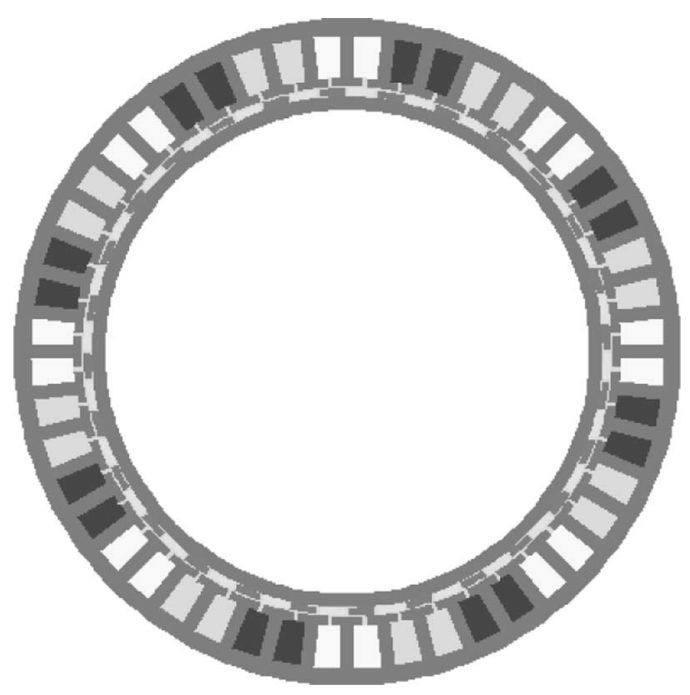

Fig. 4. Cross section of 6-kW SPM machine with 48 slots and 56 poles $(\mathrm{SPP}=2 / 7)$.

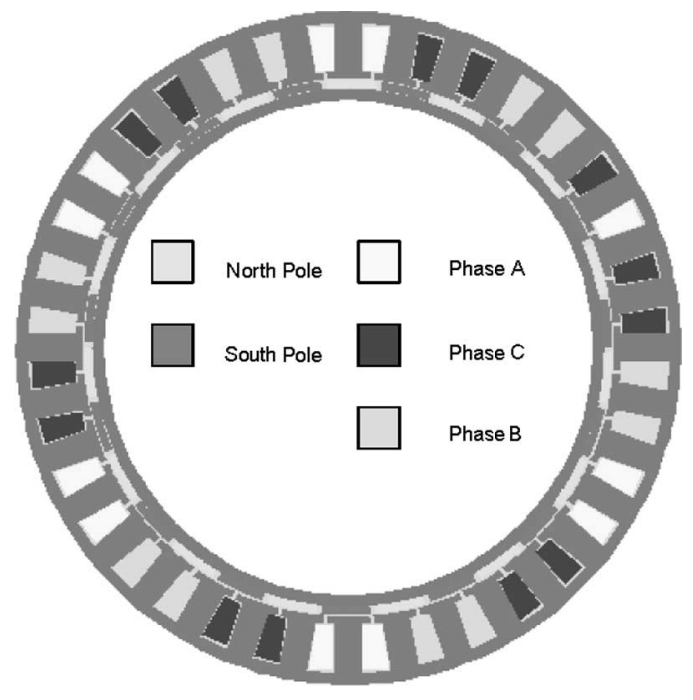

Fig. 5. Cross section of 6-kW SPM machine with 36 slots and 30 poles $(\mathrm{SPP}=2 / 5)$.

the designed machines can deliver constant power over wide speed ranges to meet the performance requirements.

1) Length and Mass: Some useful comparisons among these four machines are presented as bar charts, drawing on the machine design and performance data in Table I. Fig. 7 shows that the total length of the machine gradually reduces as the number of poles increases. This trend is expected due to a reduction in the stator winding end-turn length as the pole number increases. The 36-s/42-p (SPP = 2/7) and the 36-s/30-p (SPP = 2/5) designs have the same total length because they have the same number of stator slots.

Following a similar trend, Fig. 8 shows that there is reduction in the total mass of the machine as the number of poles increases. This mass reduction is principally due to the reduction in the back-iron thickness, a well-known trend associated with increases in the pole number. This reduction in the back-iron thickness is reflected in the calculated iron mass values found in Table I.
TABLE I

SuMMARY OF PARAMETERS AND PERFORMANCE METRICS FOR FOUR SPM MACHINE DESIGNS With DIFFERENT SLOT/POLE NuMBERS

\begin{tabular}{|c|c|c|c|c|}
\hline & $\mathbf{2 4 s / 2 8 p}$ & $\mathbf{3 6 s / 4 2} \mathbf{p}$ & $\mathbf{4 8} \mathbf{s} / \mathbf{5 6}$ & $\mathbf{3 6} / \mathbf{3 0} \mathbf{p}$ \\
\hline Slot/Pole/Phase (SPP) & $2 / 7$ & $2 / 7$ & $2 / 7$ & $2 / 5$ \\
\hline Outer Diameter [mm] & 272 & 272 & 272 & 272 \\
\hline Active Length [mm] & 60 & 60 & 60 & 60 \\
\hline Air Gap Thickness [mm] & 0.635 & 0.635 & 0.635 & 0.635 \\
\hline Total Length [mm] & 79 & 73 & 69 & 73 \\
\hline Char. Current, $I_{c h}[\mathrm{~A} \mathrm{rms}]$ & 113.7 & 113.7 & 114.4 & 113.8 \\
\hline Rated Current, $I_{R}[\mathrm{~A} \mathrm{rms}]$ & 110 & 110 & 110 & 110 \\
\hline FW_index $\left(I_{c h} / I_{R}\right)$ & 1.03 & 1.03 & 1.04 & 1.03 \\
\hline Copper Mass [kg] & 3.8 & 3.3 & 4 & 3.3 \\
\hline Iron Mass [kg] & 8.8 & 7.1 & 4.7 & 7.1 \\
\hline Magnet Mass [kg] & 0.82 & 0.87 & 0.9 & 0.87 \\
\hline Total Mass [kg] & 13.4 & 11.3 & 9.6 & 11.3 \\
\hline Magnet Remanent Flux & 1.1 & 0.9 & 0.91 & 0.76 \\
\hline Density, $B_{r}[$ Tesla] & & & & \\
\hline Stator Turns, $N_{s}[$ Turns] & 22 & 26 & 27 & 31 \\
\hline No. of Parallel Paths & 4 & 6 & 8 & 6 \\
\hline Rated Current Density & 3.1 & 3.8 & 2.7 & 4.3 \\
\hline [A/mm ${ }^{2}$ ] & & & & \\
\hline Slot Fill Factor [pu] & 0.7 & 0.7 & 0.7 & 0.7 \\
\hline Rotor Active Volume [m $\left.{ }^{3}\right]$ & 0.00186 & 0.0021 & 0.00221 & 0.00207 \\
\hline Air Gap Shear Stress [psi] & 2.5 & 2.24 & 2.1 & 2.34 \\
\hline LCM (S,2P) & 17.2 & 15.4 & 14.5 & 16.1 \\
\hline Slot Opening Width [mm] & 168 & 252 & 332 & 180 \\
\hline Efficiency at 6000 rpm [\%] & 90 & 91 & 90.6 & 91.6 \\
\hline
\end{tabular}

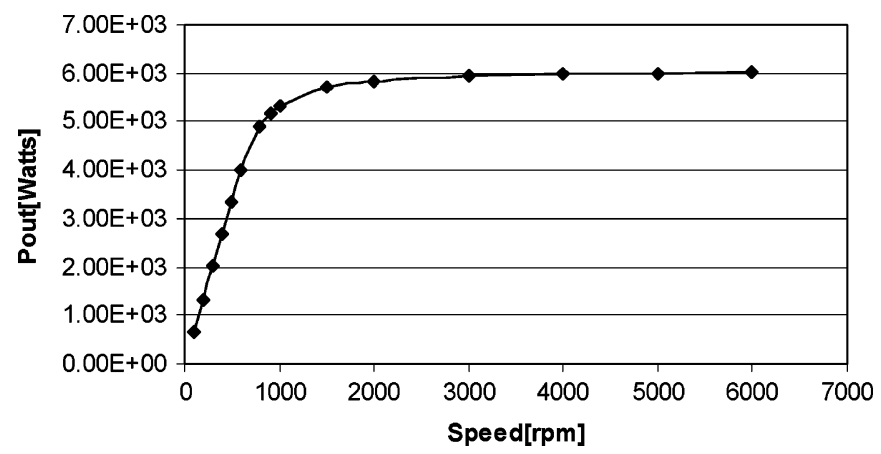

Fig. 6. Calculated power versus speed envelope of the four SPM machine designs with different slot/pole number configurations.

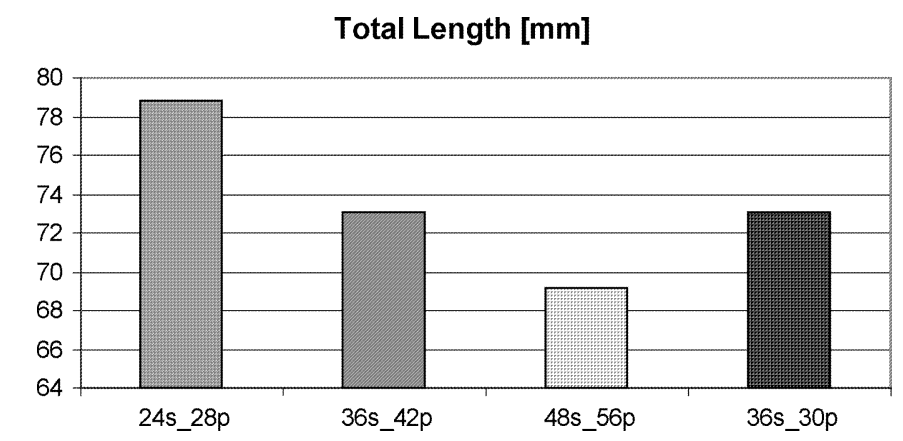

Fig. 7. Comparison of the total length of the four SPM machine designs with different slot/pole number configurations. 


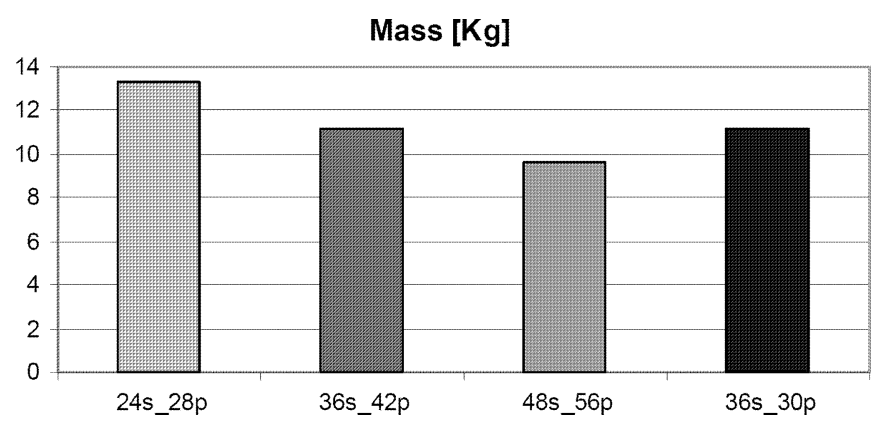

Fig. 8. Comparison of the total mass of the four SPM machine designs with different pole numbers.

\section{$\mathrm{Br}$ [Tesla]}

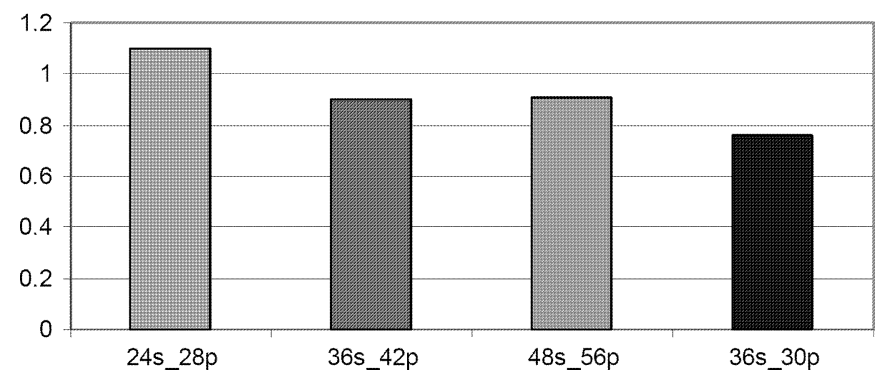

Fig. 9. Comparison of the magnet remanent flux density $B_{\mathrm{r}}$ for the four machine designs with different pole numbers.

Only one of the four designs in Table I (36-s/30-p) belongs to the SPP $=2 / 5$ family, while the other three fall into the SPP $=2 / 7$ family. Results of this study, combined with other evidence not presented here, indicate that the machine performance results that can be achieved with configurations in the $\mathrm{SPP}=2 / 7$ and $2 / 5$ families are very similar [1], [6], [7]. This is most evident by comparing the Table I results for the 36-s/42-p $(\mathrm{SPP}=2 / 7)$ and $36-\mathrm{s} / 30-\mathrm{p}(\mathrm{SPP}=2 / 5)$ configurations that have identical stators but different rotors.

2) $B_{r}$ Remanent Flux Density: Fig. 9 shows a comparison of the magnet remanent flux density $B_{\mathrm{r}}$ among the four machines. The number of turns and the magnet remanence in each machine are determined by simultaneously solving equations for the optimal flux-weakening condition (1) and the corner speed requirement [1], [3], [4]. It can be seen that the $B_{\mathrm{r}}$ value tends to rise as the number of poles is reduced within the same SPP family. This can be a limiting factor when designs with even lower numbers of poles (e.g., 12-s/14-p) are attempted.

In fact, the 12-s/14-p combination represents the SPP $=2 / 7$ family member with the lowest number of stator slots and poles. This configuration is not included in Table I comparison because it was not possible to find a practical design that could meet all of the size and performance constraints that were adopted in this design exercise. In particular, the required value of $B_{\mathrm{r}}$ needed to meet the conditions for optimal flux weakening rises to $1.6 \mathrm{~T}$ with the 12-s/14-p configuration, beyond the maximum limits of the NdFeB permanent magnets considered in this investigation.

Even if such magnets were available, the volume and mass of the 12-s/14-p machine is significantly higher than any of the candidate machines in Table I. This is not totally unexpected, since it is well known that the back-iron thickness in any ac machine must increase as the number of poles is reduced to avoid iron saturation. These results suggest that the fractionalslot concentrated winding approach to achieving optimum flux weakening conditions in SPM machines becomes progressively more challenging to successfully apply as the numbers of stator slots and poles are reduced.

To quantitatively explain the tendency towards higher $B_{\mathrm{r}}$ values for lower number of poles, the 12-s/14-p winding configuration ( $N_{1}$ turns/coil, $p_{1}=7$ pole pairs, and $B_{r 1}$ magnet remanence) will be compared to the 36-s/42-p winding ( $N_{2}$ turns/coil, $p_{2}=21$ pole pairs, and $B_{r 2}$ magnet remanence). On the basis of the definition of the machine's characteristic current (1), the basic scaling relationship between $B_{\mathrm{r}}$ and the number of winding turns $N$ can be derived as follows:

$$
I_{\mathrm{ch}} \equiv \frac{\Psi_{\mathrm{m}}}{L_{d}} \alpha \frac{N B_{\mathrm{r}}}{N^{2}}=k \frac{B_{\mathrm{r}}}{N}
$$

where $k$ is a constant that depends on the machine's dimensions.

For both winding configurations to meet the condition for optimal flux weakening with the same rated current, they must have the same value of characteristic current. Using (2), this observation leads to

$$
k_{1} \frac{B_{\mathrm{r} 1}}{N_{1}}=k_{2} \frac{B_{\mathrm{r} 2}}{N_{2}} .
$$

For the same rated voltage, and corner speed, $N_{1}$ and $N_{2}$ are related as follows [8]:

$$
N_{1}=\sqrt{\frac{p_{2}}{p_{1}}} N_{2}=\sqrt{\frac{21}{7}} N_{2}=\sqrt{3} N_{2} .
$$

Combining (3) and (4) leads to

$$
B_{\mathrm{r} 1}=\sqrt{3} \frac{k_{1}}{k_{2}} B_{\mathrm{r} 2} .
$$

This relationship indicates that the required value of $B_{\mathrm{r}}$ to meet the optimal flux-weakening condition increases with lower pole-pair values as $1 / \sqrt{p}$.

3) Current Density: Values Table I show that all four designs have relatively low rated-current densities, i.e., less than $5 \mathrm{~A} / \mathrm{mm}^{2}$, so significant thermal limitations are not expected. However, it must be pointed out that all four designs assume a high stator slot fill factor of $70 \%$ (defined as ratio of copper area to slot area). This assumption is based on reported slot fill factor values in the literature [10] for segmented stator stuctures and prepressed concentrated stator windings. Adoption of a lower value for the slot fill factor would have to be accompanied by an inversely higher current density in order to achieve the same torque production performance with the same stator laminations and stack length.

4) Cogging Torque: Table I also provides a comparison of the lowest common multiple (LCM) of the number of stator slots and the number of poles. This LCM value is significant because it corresponds to the cogging torque harmonic frequency [11]. It can be seen that each of the four designs has a high cogging torque frequency, leading to reduced cogging torque magnitudes. 


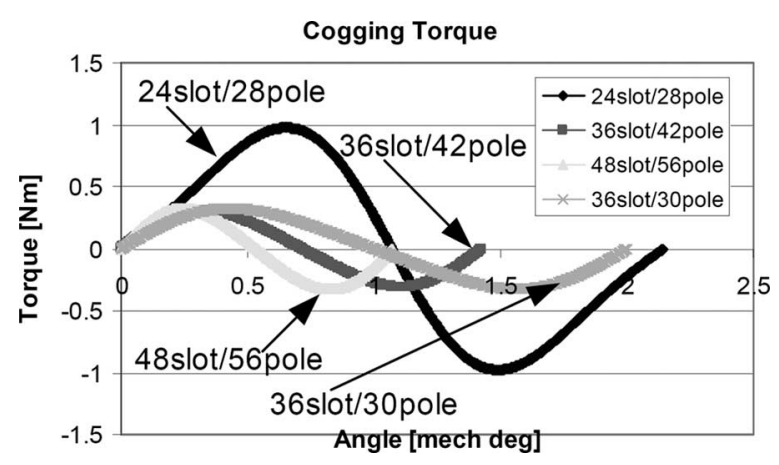

Fig. 10. Predicted cogging torque waveforms for the four machine designs with different pole numbers plotted versus mechanical angular position.

The analytically predicted cogging torque waveforms for the four designs are plotted on the same axes in Fig. 10 for ease of comparison. The calculated peak-to-peak cogging torque amplitudes of these designs are appealingly low, varying between $1 \%$ of the rated torque for the $48-\mathrm{s} / 56-\mathrm{p}$ design to $3 \%$ for the 24-s/28-p design.

5) Efficiency: One of the important machine performance metrics is efficiency. There are two major contributing factors to the machine losses in addition to the stator copper losses. One of these is the iron core losses. The adoption of high pole numbers and the presence of significant subharmonic and harmonic magnetic flux components [12] makes it important to laminate the rotor core in addition to the stator.

The impact of the high frequencies on core losses is partially offset by two factors. First, the thickness of the stator and rotor back iron is less with high pole numbers, helping to reduce the iron mass and associated core losses. In addition, the reduction of the machine flux amplitude in the high-speed flux weakening regime also helps to reduce the iron core losses.

A key condition for achieving high efficiency in SPM machines with fractional-slot concentrated windings is minimization of the eddy-current losses in the rotor magnets. Magnet losses can be reduced by using bonded magnets, which have significantly higher resistivity compared to sintered magnets. Segmenting the rotor magnets can also significantly suppress the magnet eddy-current losses, and this becomes particularly important for sintered magnets [13]. The issue of magnet losses in such machines is discussed in more details in other papers [13], [14].

Values in Table I show that all four designs have comparable predicted efficiency values at the top speed falling into the range of $90 \%$ to $92 \%$. These efficiency values are based on the assumption that each magnet pole is segmented into four pieces in the peripheral direction in order to reduce the eddy-current losses in the magnets. Although efficiency and losses are not the major topics of this paper, the Table I results support the conclusion that careful machine design yields fractional-slot concentrated winding SPM machines with efficiencies that typically exceed $90 \%$ [15], [16].

Summarizing, this design exercise has shown that SPM machines using fractional-slot concentrated windings to achieve wide constant-power speed ranges generally scale well with
TABLE II

SuMMARY OF PARAMETERS AND PERFORMANCE METRICS FOR THREE 36S/42P SPM MACHINE DESIGNS WITH DIFFERENT ASPECT RATIOS

\begin{tabular}{|c|c|c|c|}
\hline & $\mathrm{AR}=4.5$ & $\mathbf{A R}=\mathbf{2}$ & $\mathbf{A R}=\mathbf{1}$ \\
\hline Outer Diameter [mm] & 272 & 207.3 & 165.1 \\
\hline Active Length [mm] & 60 & 103.3 & 162.9 \\
\hline Air Gap Thickness [mm] & 0.635 & 0.635 & 0.635 \\
\hline Total Length [mm] & 73 & 113.2 & 170.8 \\
\hline Char. Current, $I_{c h}$ [Amps rms] & 113.7 & 113.8 & 117 \\
\hline Rated Current, $I_{R}$ [Amps rms] & 110 & 110 & 110 \\
\hline FW_index $\left(I_{c h} / I_{R}\right)$ & 1.03 & 1.03 & 1.06 \\
\hline Copper Mass [kg] & 3.3 & 2.75 & 2.64 \\
\hline Iron Mass [kg] & 7.1 & 7.9 & 6.8 \\
\hline Magnet Mass [kg] & 0.87 & 1.13 & 1.43 \\
\hline Total Mass $[\mathrm{kg}]$ & 11.3 & 11.8 & 10.9 \\
\hline $\begin{array}{l}\text { Magnet Remanent Flux Density, } \\
\qquad B_{r}[\text { Tesla }]\end{array}$ & 0.9 & 0.87 & 0.9 \\
\hline Stator Turns, $N_{s}$ [Turns] & 26 & 31 & 31 \\
\hline No. of Parallel Paths & 6 & 6 & 6 \\
\hline Rated Current Density [A/mm $\left.{ }^{2}\right]$ & 3.8 & 5.37 & 6.5 \\
\hline Rated Stator Copper Loss [W] & 111 & 199 & 284 \\
\hline Rotor Active Volume $\left[\mathrm{mm}^{3}\right]$ & 0.0021 & 0.00199 & 0.00198 \\
\hline $\begin{array}{r}\text { Air Gap Shear Stress [psi] } \\
{[\mathrm{kPa}]}\end{array}$ & $\begin{array}{l}2.52 \\
17.4\end{array}$ & $\begin{array}{l}2.33 \\
16.1\end{array}$ & $\begin{array}{l}2.34 \\
16.1\end{array}$ \\
\hline Slot Opening Width [mm] & 2.5 & 1.4 & 1.4 \\
\hline
\end{tabular}

changes in the number of poles. However, special care is needed when reducing the number of stator slots and poles to minimize the machine weight and volume.

\section{B. Scalability With Diameter-to-Length Aspect Ratio}

The aforementioned SPM machines have diameter-to-length $(D / L)$ aspect ratios (AR) in the vicinity of 4.5 because they were designed with a direct-drive automotive starter/alternator application in mind. The 36-s/42-p design ( SPP $=2 / 7$ ) was selected as the baseline for investigating the impact of variable AR on the SPM motor design. More specifically, new 36-s/42-p SPM motor designs meeting the conditions for optimum flux weakening were developed having $D / L$ AR values of 1 and 2 to compare with the $\mathrm{AR}=4.5$ design. All designs were constrained to have the same active volume (i.e., $D^{2} L$ is the same for all three designs) and the same rated rotor torque and speed values.

Table II summarizes the key parameters and design variables of the three designs. As expected, the machine lengths increase while the diameters decrease as the value of AR is reduced. The table values show that all three designs have near-unity values of FW_index, indicating that each machine has been designed to closely approach the conditions for optimal flux weakening.

Figs. 11 and 12 show that the stator winding current density and the copper losses both increase as the $D / L \mathrm{AR}$ is reduced. This trend is consistent with fact that the stator slot area proportionally decreases with the machine cross-sectional area, but the current per slot must stay roughly constant in order to produce the same force per unit area (i.e., shear stress) in the air gap. As a result of this scaling trend, the machine phase resistance and stator copper losses increase as the AR is reduced. The 


\section{Copper Losses [Watts]}

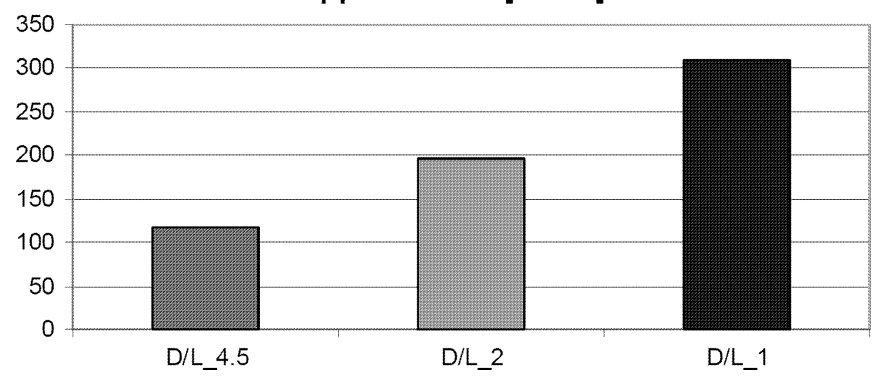

Fig. 11. Comparison of the average copper losses of the three 36-s/42-p SPM machines with different $D / L$ aspect ratios.

Steady State Current Density [A/mm^2]

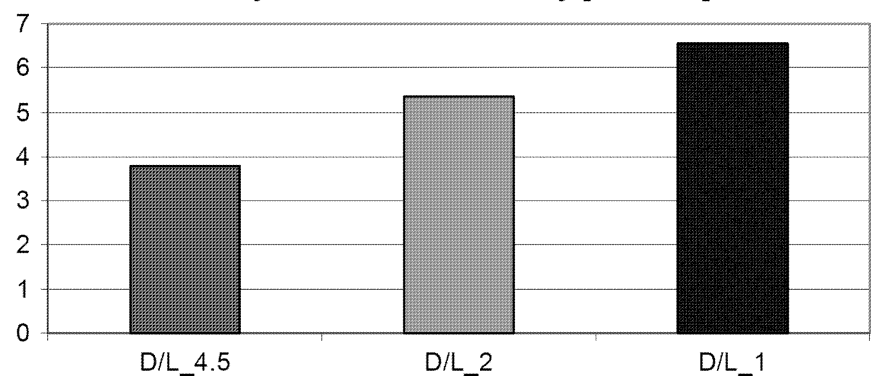

Fig. 12. Comparison of the steady-state current density of the three $36-\mathrm{s} / 42-\mathrm{p}$ SPM machines with different $D / L$ aspect ratios.

steady-state current density values for all three designs are still within acceptable limits for liquid-cooled machines.

Alternatively, this tradeoff study could have been conducted with a constraint of equal slot current density for each of the three designs with different AR values. However, this would require the $D^{2} L$ active volume of the machines to increase as the AR is reduced, causing an associated increase in machine mass.

Since the $D^{2} L$ active machine volume is held constant in this study, the three designs have very similar total masses. In addition, the three machines have nearly the same active rotor volumes and, hence, very similar air gap shear stress values. Each of the three designs has a very low peak-to-peak cogging torque that does not exceed $1.5 \%$ of the rated torque for the same reasons discussed in Section II-A4.

Overall, the conclusion can be drawn that SPM machines designed to achieve optimal flux-weakening conditions scale quite well over a wide range of $D / L$ AR values. However, the study results show that a penalty in either the stator copper losses or the machine's active volume (hence, mass) must be accepted as the value of the AR is decreased in order to meet the same torque-speed operating requirements.

\section{Scalability With Machine Power Rating}

To explore the scalability of the optimal flux-weakening concept with output power, additional SPM machines were designed with output power ratings of 1 and $60 \mathrm{~kW}$. The same corner point and maximum speeds (600 and $6000 \mathrm{r} / \mathrm{min}$, respectively) are retained for all three designs, and only the torque requirement is scaled at each speed in direct proportion to the rated power. The $6 \mathrm{~kW}$ 36-s/42-p SPM direct-drive machine used as the baseline
TABLE III

Summary of PARAMETERS AND PERFORMANCE METRICS FOR THREE 36S/42P SPM MAChINE DESIGNS With DifFERENT POWER RATINGS

\begin{tabular}{|c|c|c|c|}
\hline & $\begin{array}{l}\text { Pout }= \\
1 \mathrm{~kW}\end{array}$ & $\begin{array}{l}\text { Pout }= \\
6 \mathrm{~kW}\end{array}$ & $\begin{array}{l}\text { Pout }= \\
60 \mathrm{~kW}\end{array}$ \\
\hline Outer Diameter $[\mathrm{mm}]$ & 149.7 & 272 & 520.3 \\
\hline Active Length [mm] & 33 & 60 & 114.8 \\
\hline$D / L$ Aspect Ratio (AR) & 4.53 & 4.54 & 4.53 \\
\hline Air Gap Length [mm] & 0.635 & 0.635 & 0.635 \\
\hline $\begin{array}{l}\text { Active Volume per kW } \\
{\left[\mathrm{cm}^{3} / \mathrm{kW}\right]}\end{array}$ & 580.8 & 581.1 & 406.8 \\
\hline Total Length [mm] & 40 & 73 & 141.6 \\
\hline Char. Current, $I_{c h}$ [Amps rms] & 123.3 & 113.7 & 514 \\
\hline Rated Current, $I_{R}$ [Amps rms] & 110 & 110 & 511 \\
\hline FW_index $\left(I_{c h} / I_{R}\right)$ & 1.1 & 1.03 & 1.01 \\
\hline Copper Mass [kg] & 0.64 & 2.75 & 15.2 \\
\hline Iron Mass [kg] & 1.1 & 7.9 & 46.1 \\
\hline Magnet Mass [kg] & 0.25 & 1.13 & 6.4 \\
\hline Total Mass [kg] & 2.0 & 11.8 & 68 \\
\hline $\begin{array}{l}\text { Magnet Remanent Flux } \\
\text { Density, } B_{r} \text { [Tesla] }\end{array}$ & 0.94 & 0.87 & 1.1 \\
\hline Stator Turns, $N_{s}[$ Turns $]$ & 16 & 31 & 11 \\
\hline No. of Parallel Paths & 6 & 6 & 6 \\
\hline Rated Current Dens. [A/mm²] & 6.5 & 5.37 & 3 \\
\hline Rated Armature Loss [W] & 67 & 199 & 347 \\
\hline $\begin{array}{r}\text { Air Gap Shear Stress [psi] } \\
{[\mathrm{kPa}]}\end{array}$ & $\begin{array}{c}2.6 \\
17.9\end{array}$ & $\begin{array}{l}2.33 \\
16.1\end{array}$ & $\begin{array}{c}2.9 \\
20.0\end{array}$ \\
\hline Slot Opening Width [mm] & 2 & 2 & 2.5 \\
\hline
\end{tabular}

in the preceding scalability studies was used again in this power scaling investigation. All three machines have the same number of stator slots and poles. The predicted power versus speed characteristics for all three SPM machines have nearly identical shapes as shown previously in Fig. 6, with only the vertical axes scaled to correspond to the machine's rated power. These design exercises have shown that the optimal flux weakening using fractional-slot concentrated windings can be achieved over this complete power range.

Table III summarizes the calculated parameters of all three designs. The higher current density in the case of the 1-kW machine is caused by the same scaling effect discussed in Section II-B. That is, maintaining the same total Amp-turns in each slot has the desirable effect of holding the air gap shear stress roughly constant if the remanent flux density $B_{\mathrm{r}}$ is also unchanged. However, this design approach makes it necessary to increase the current density or the active volume per kilowatt as the machine diameter is reduced. In this case, the active volume per kilowatt was held constant for the 1- and 6-kW machines, making it necessary to accept a higher stator slot current density in the 1-kW machine.

While this comparison indicates that the use of fractionalslot concentrated stator windings maintains its usefulness as a means of achieving optimal flux-weakening conditions over a wide machine power range, there are some practical issues that deserve comment. More specifically, the practicality of retaining high numbers of stator slots and poles gradually becomes more difficult as the diameter of the machine is reduced.

In this particular comparison, the choice of a high $D / L$ AR value of 4.53 makes it reasonable to adopt a 36-s/42-p 


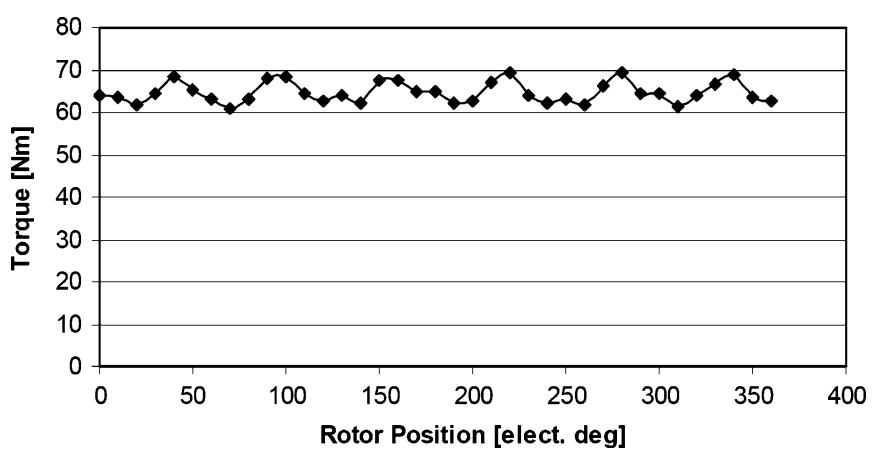

Fig. 13. FEA predicted torque waveform for the 24-s/28-p 6-kW machine design at $600 \mathrm{r} / \mathrm{min}$ with sinusoidal current excitation.

configuration even for the lowest considered power rating. However, if a lower AR or a lower power rating had been considered, the machine diameter would drop to the point that such high slot and pole numbers would become increasingly impractical.

Of course, choice of a different fractional-slot configuration in either the SPP $=2 / 5$ or $2 / 7$ families with lower numbers of stator slots and poles (e.g., 24-s/28-p or 12-s/14-p) would be a valid approach to relieving this problem. However, as discussed in Section II-A, the adoption of such configurations makes it progressively more difficult to develop attractive machine designs because of trends toward higher values of $B_{\mathrm{r}}$, machine volume, and mass as the slot and pole numbers are reduced.

\section{FEA RESULTS}

The analytical results for all designs presented in the previous sections have been verified using FEA. Two FEA packages have been used: MagNet 2D by Infolytica and Maxwell 2D by Ansoft. The peculiarities of the fractional-slot configurations make it impossible to model only a single pole in the FEA investigations by taking advantage of the natural symmetries that exist with integral values of SPP. Instead, it is necessary to model, at a minimum, the basic repeating stator-rotor unit of the machine, such as the ones shown in Fig. 1 for the SPP $=2 / 7$ and $2 / 5$ machine families.

Detailed comparisons of the predicted machine parameters and performance characteristics for fractional-slot concentrated winding SPM machines using the closed-form analysis and FEA tools have been presented elsewhere [1], [8] and will not be repeated here. However, it can be stated that the results of these comparisons are very good in almost all cases. For example, the difference between the calculated rms magnet flux linkage values using closed-form analysis and FEA is less than $0.5 \%$ for the 36-s/42-p SPM machine design. Predicted ripple and cogging torque waveforms also agree very well with both analysis techniques. Taken together, these results raise confidence that the predicted performance characteristics of the various SPM machine designs are credible.

The FEA predicted torque ripple waveforms for the 24-s/28-p $(\mathrm{SPP}=2 / 7) 6-\mathrm{kW}$ machine design at the corner speed $(600$ $\mathrm{r} / \mathrm{min}$ ) with sinusoidal current excitation is shown in Fig. 13. The peak-to-peak ripple is approximately $8 \%$ of the machine rated torque $(64 \mathrm{~N} \cdot \mathrm{m})$. The other designs have similar torque

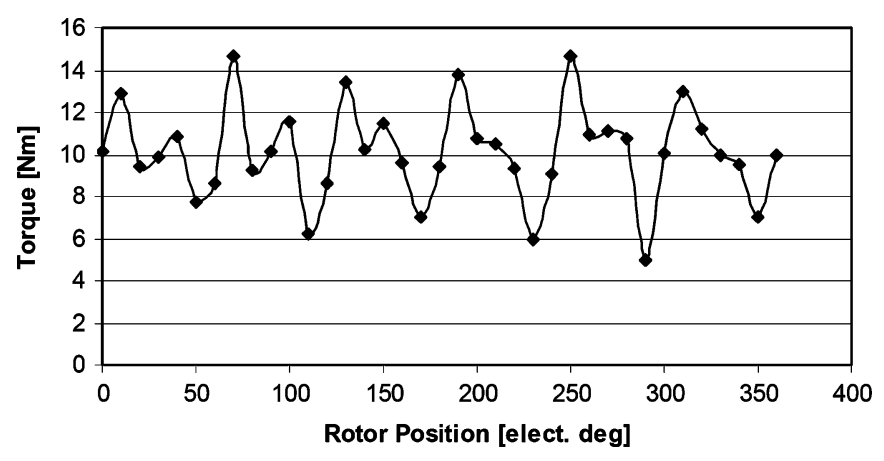

Fig. 14. FEA predicted torque waveform for the 24-s/28-p 6-kW machine design at $6000 \mathrm{r} / \mathrm{min}$ with six-step voltage excitation.

profiles with peak-to-peak values ranging from 9\% (36-s/42-p) to $13 \%(48-\mathrm{s} / 56-\mathrm{p})$ of the rated torque.

The FEA predicted torque ripple for the 24-s/28-p design at the top speed $(6000 \mathrm{r} / \mathrm{min})$ with six-step voltage excitation is shown in Fig. 14. Even though the torque ripple is significant as a percentage of the average torque, the machine inertia behaves as an effective mechanical low-pass filter, so the resulting speed ripple under these high-speed conditions will typically be too low to cause any problems. The other machine designs have similar torque waveforms.

\section{CONCLUSION}

SPM synchronous machines can now be considered as serious candidates for applications requiring wide speed ranges of constant-power operation by properly designing the machine with fractional-slot concentrated windings. This paper provides a contribution by demonstrating that the key design objective of achieving optimal flux weakening can be achieved over a wide range of application conditions. Key results of this scaling investigation include the following.

1) If the SPP value is fixed, the conditions for optimal flux weakening can be achieved with a variety of stator slot/rotor pole combinations that share this same SPP value. However, finding machine designs that meet the conditions for optimal flux weakening tends to be easier as the slot and pole numbers are increased. Conversely, selection of SPP family members with lower slot and pole numbers has the undesired effects of increasing the machine volume, mass, and magnet remanent flux density $\left(B_{\mathrm{r}}\right)$ values.

2) The ability to meet the design conditions for optimal flux weakening is not limited by the machine $D / L \mathrm{AR}$, making it possible to apply the technique over a wide range of diameter and length combinations. However, this scaling investigation has shown that the machine active volume and/or slot current density tend to increase as the $D / L$ AR is reduced for the same power level. Any need to reduce the number of stator slots and rotor poles as the machine diameter is reduced will further increase the upward pressure on machine volume and mass.

3) Design examples with SPM machines rated from 1 to $60 \mathrm{~kW}$ indicate that the optimal flux weakening can be 
achieved in SPM machines with fractional-slot concentrated windings over a wide range of machine power ratings. However, here again, the machine active volume per kilowatt and/or current density tend to increase as the machine power rating and diameter are reduced.

Taking the broadest possible view, the results of this scaling study suggest that the fractional-slot concentrated winding technique for achieving wide constant-power speed ranges in SPM machines is most conveniently applied to large-diameter machines that are compatible with high stator slot and pole numbers. Conversely, the application of this technique poses increasing challenges to the designer as the machine diameter and the maximum acceptable numbers of stator slots and rotor poles are reduced. As the understanding of fractional-slot concentrated winding configurations deepens, there is an increasing evidence that the technical obstacles associated with low slot and pole numbers are surmountable in many of these cases.

On the basis of the promising results demonstrated to date in this paper and others, work is continuing in many laboratories to address the remaining challenges that could limit the successful development of SPM machines for extended-speed range applications. These challenges include the potential for unacceptably high rotor losses and the danger presented by high back-emf voltage amplitudes at speeds high above the corner speed value. Progress on addressing these issues will be presented in future papers.

\section{ACKNOWLEDGMENT}

The authors would like to thank Prof. D. W. Novotny for his many valuable technical discussions. The authors also acknowledge the Wisconsin Electric Machines and Power Electronics Consortium (WEMPEC) for use of its facilities.

\section{REFERENCES}

[1] A. M. EL-Refaie and T. M. Jahns, "Optimal flux weakening in surface PM machines using fractional-slot concentrated windings," IEEE Trans. Ind. Appl., vol. 41, no. 3, pp. 790-800, May-Jun. 2005.

[2] F. Magnussen, P. Thelin, and C. Sadarangani, "Performance evaluation of permanent magnet synchronous machines with concentrated and distributed windings including the effects of field-weakening," presented at the 2004 IEE Power Electronics, Machines and Drives Conference (PEMD’04), Edinburgh, Apr. 2004.

[3] R. F. Schiferl and T. A. Lipo, "Power capability of salient pole permanent magnet synchronous motor in variable speed drive applications," IEEE Trans. Ind. Appl., part 1, vol. 26, no. 1, pp. 115-123, Jan.-Feb. 1990.

[4] T. M. Jahns, "Flux weakening regime operation of an IPM synchronous motor drive," IEEE Trans. Ind. Appl., vol. IA-23, no. 4, pp. 681-689, Jul.-Aug. 1987.

[5] W. L. Soong and T. J. E. Miller, "Field weakening performance of brushless synchronous AC motor drives," IEE Proc.-Electr. Power Appl., vol. 141, no. 6, pp. 331-340, Nov. 1994.

[6] J. Cros and P. Viarouge, "Synthesis of high performance PM motors with concentrated windings," IEEE Trans. Energy Convers., vol. 17, no. 2, pp. 248-253, Jun. 2002.

[7] F. Magnussen and C. Sadarangani, "Winding factors and joule losses of permanent magnet machines with concentrated windings," in Proc. IEEEIEMDC'03, vol. 1, Madison, WI, Jun. 1-4, 2003, pp. 333-339.

[8] A. M. EL-Refaie, T. M. Jahns, and D. W. Novotny, "Analysis of surface permanent magnet machines with fractional-slot concentrated windings," IEEE Trans. Energy Convers., vol. 21, no. 1, Mar. 2006, pp. 34-43.

[9] E. C. Lovelace "Optimization of a magnetically saturable interior PM synchronous machine drive," Ph.D. thesis, Dept. Elec. Eng. \& Comp. Sci., MIT, Cambridge, MA, 2000.
[10] A. G. Jack, B. C. Mecrow, P. G. Dickinson, D. Stephenson, J. S. Burdess N. Fawcett, and J. T. Evans, "Permanent magnet machines with powdered iron cores and pressed windings," IEEE Trans. Ind. Appl., vol. 36, no. 4, pp. 1077-1084, Jul.-Aug. 2000.

[11] Z. Q. Zhu and D. Howe, "Influence of design parameters on cogging torque in permanent magnet machines," IEEE Trans. Energy Convers., vol. 15 , no. 4 , pp. 407-412, Dec. 2000.

[12] C. Mi, G. R. Slemon, and R. Bonert, "Modeling of iron losses of permanent-magnet synchronous motors," IEEE Trans. Ind. Appl., vol. 39, no. 3, pp. 734-742, May-Jun. 2003.

[13] K. Atallah, D. Howe, P. H. Mellor, and D. A. Stone, "Rotor loss in permanent-magnet brushless AC machines," IEEE Trans. Ind. Appl., vol. 36, no. 6, pp. 1612-1618, Nov.-Dec. 2000.

[14] Z. Q. Zhu, K. Ng, N. Schofield, and D. Howe, "Improved analytical modelling of rotor eddy current loss in brushless machines equipped with surface-mounted permanent magnets," IEE Proc.-Electric Power Appl., vol. 151, no. 6, pp. 641-650, Nov. 2004.

[15] A. M. EL-Refaie and T. M. Jahns, "Comparison of synchronous PM machines types for wide constant-power speed range operation," Rec. 40th IAS Annu. Meeting, vol. 2, Oct. 2-6, 2005, pp. 1015-1022.

[16] A. M. EL-Refaie, T. M. Jahns, P. J. McCleer, and J. W. McKeever, "Experimental verification of optimal flux weakening in surface PM machines using concentrated windin," IEEE Trans. Ind. Appl., vol. 42, no. 2, Mar.Apr. 2006, pp. 443-453.

[17] T. A. Lipo, Introduction to AC Machine Design. Madison, WI: Wisconsin Power Electronics Research Center, Univ. Wisconsin Press, 1996.

[18] J. R. Hendershot Jr. and T. J. E. Miller, Design of Brushless PermanentMagnet Motors. Oxford: Clarendon, 1994.

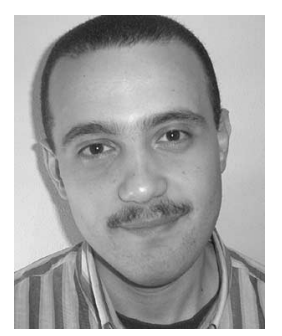

Ayman M. EL-Refaie (M'06) received the B.Sc. and M.Sc. degrees from Cairo University, Giza, Egypt, in 1995 and 1998, respectively, both in electrical power engineering. He received the M.Sc. and Ph.D. degrees in electrical engineering from the University of Wisconsin, Madison, in 2002 and 2005, respectively.

Between 1995 and 1998, he was an Assistant Lecturer at Cairo University and the American University in Cairo. Between 1999 and 2005, he has been a Research Assistant at the University of Wisconsin, Madison, in the Wisconsin Electric machines and Power Electronics Consortium (WEMPEC). Currently, he is an Electrical Engineer at the Electrical Machines and Drives Laboratory, GE Global Research Center, Niskayuna, NY. His interests include electrical machines and drives.

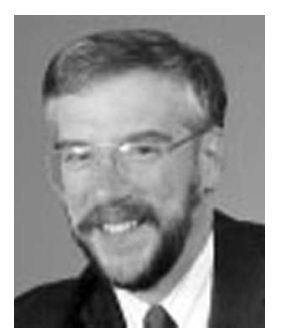

Thomas M. Jahns (S'73-M'79-SM'91-F'93) received the S.B. and S.M. degrees in 1974 and the Ph.D. degree in 1978 from the Massachusetts Institute of Technology (MIT) Cambridge, MA, all in electrical engineering.

Prior to coming to University of WisconsinMadison, he was with GE Corporate Research and Development (now GE Global Research Center) in Schenectady, NY, for 15 years, where he pursued new power electronics and motor drive technology in a variety of research and management positions. He joined the faculty of the UW-Madison in 1998 as a Professor in the Department of Electrical and Computer Engineering, where he is also an Associate Director of the Wisconsin Electric Machines and Power Electronics Consortium (WEMPEC). His research interests include permanent magnet synchronous machines for a variety of applications ranging from high-performance machine tools to low-cost appliance drives. During 1996-1998, he conducted a research sabbatical at the MIT, where he directed research activities in the area of advanced automotive electrical systems and accessories as Codirector of an industrysponsored automotive consortium.

Dr. Jahns is the recipient of the 2005 IEEE Nikola Tesla Award. He was awarded the William E. Newell Award by the IEEE Power Electronics Society (PELS) in 1999. He has been recognized as a Distinguished Lecturer by the IEEE Industry Applications Society (IAS) during 1994-1995 and by IEEEPELS during 1998-1999. He has served as President of PELS (1995-1996) and as Division II Director on the IEEE Board of Directors (2001-2002). 